\section{(2) OPEN ACCESS}

\title{
Challenges and opportunities of COVID-19 for gastroenterology and hepatology services
}

\author{
Tony C Tham (D) , ${ }^{1,2}$ Andrew C Douds, ${ }^{3,4}$ Rupert Ransford ${ }^{5,6}$
}

${ }^{1}$ Immediate past Chair, British Society of Gastroenterology Clinical Services and Standards Committee, London, UK

${ }^{2}$ Division of Gastroenterology, Ulster Hospital, Belfast, Northern Ireland, United Kingdom

${ }^{3}$ Department of

Gastroenterology, Norfolk and Norwich University Hospital NHS Trust, Norwich, UK

${ }^{4}$ Chair, British Society of Gastroenterology Clinical

Services and Standards

Committee, London, UK

${ }^{5}$ Department of

Gastroenterology, Hereford

County Hospital, Hereford, UK

${ }^{6}$ Deputy Chair, British Society

of Gsatroenterology Clinical

Services and Standards

Committee, London, UK

Correspondence to

Dr Tony C Tham,

Gastroenterology, Ulster Hospital, Dundonald, Belfast BT16 1RH,

UK; tctham1234@gmail.com

Received 2 July 2020

Revised 13 August 2020

Accepted 15 August 2020

Published Online First

18 September 2020

\section{Check for updates}

(C) Author(s) (or their employer(s)) 2021. Re-use permitted under CC BY-NC. No commercial reuse. See rights and permissions. Published by BMJ.

To cite: Tham TC,

Douds AC, Ransford R.

Frontline Gastroenterology

2021;12:342-344.
We are all aware that the COVID-19 pandemic has had the most profound impact on society and healthcare in our lifetime. As we are now in the recovery phase of the pandemic, we have an opportunity to reboot and redesign our services including the way we work for the benefit of the patient. ${ }^{1}$ We will consider the challenges and opportunities for healthcare staff and services.

\section{HEALTH AND WELL-BEING OF STAFF}

Many of our healthcare colleagues are also patients with chronic diseases and have raised concerns about time away from work because of shielding, effect on their mental health, uncertainty about whom to talk to about their condition and confusion about receiving conflicting advice. ${ }^{2}$ Time off work has also adversely impacted on rotas and teams. Healthcare workers from a black, Asian and minority ethnic background (BAME) are also rightly worried about their own risks from COVID-19 as evidence shows that they are more disproportionately affected with more severe disease. ${ }^{3}$ Public Health England has recommended that BAME healthcare workers should be risk assessed by their employers followed by any necessary precautions. ${ }^{4}$ Even before the COVID-19 pandemic, it was recognised that the well-being of healthcare professionals is an important factor in the provision of good service ${ }^{5}$ and the stress of the pandemic has brought mental as well as physical health into sharp focus. Many gastroenterologists want to change the way they work and redesigning services provides an opportunity to improve work-life balance in addition to the quality of care for patients. Many of our colleagues during the pandemic have seen the benefits of working from home during hours that suit them and would like to continue working flexibly.

\section{TRAINING IN GASTROENTEROLOGY AND HEPATOLOGY}

This has been adversely affected by the COVID-19 pandemic with $66 \%$ of trainees not undertaking clinics and 53\% feel that they are unlikely to achieve their Annual Review of Competency Progression targets. ${ }^{6}$ Redesigning outpatient services and the flexibility now available by better utilisation of digital technology and remote consultations should increase training opportunities. Limitations of the availability of clinic rooms will be largely reduced. The significant reduction in non-value-added time for patients being assessed remotely should result in patients being even more amenable to a trainee or trainer 'sitting in' on their consultation. ${ }^{1}$

\section{RETURN OF SPECIALIST TEAMS}

The essential redeployment of healthcare staff to COVID-19-related duties has meant that gastroenterology services have been adversely affected. ${ }^{6}$ Ninety-two per cent of services have had their specialist nurses redeployed elsewhere. The British Society of Gastroenterology (BSG) recommends that the retention of specialist nurses in specialist roles is vital to help support the recovery of services by performing roles such as triaging, vetting and fielding urgent referrals from generalpractitioners and high-risk patients. ${ }^{7}$

\section{ENDOSCOPY SERVICES}

These were reduced to emergency cases only with $21 \%$ of endoscopy units undertaking cancer 2-week wait endoscopies only. Many units have recommenced 
endoscopy services based on the BSG guidance for restarting endoscopy services. ${ }^{8}$ One of the important principles is that senior clinical triage remains an essential part of the restoration of service and good clinical practice. The practice of triaging patients straight to endoscopy based on scant information from the referral needs to be reconsidered. Clinical triage based on reliable tests such as faecal immunochemical test (FIT) or validated symptom scores might change the concept of high-volume low-yield endoscopy to one of a low-volume but high-yield endoscopy.

\section{OUTPATIENT CLINICS}

Eighteen per cent had stopped doing clinics entirely during the height of the pandemic and of those still doing clinics, only $57 \%$ of their usual volume. When rebooting services, they should be centred on the patient's needs and those of society. At present, patients give time to attend hospitals with costs in terms of missed work, childcare, care of relations in addition to enormous travel costs. New ways of distance working can be more efficient and flexible, potentially improving the productivity of outpatient services and reducing the negative impact on patients and carers. Travel to and from hospital constitutes significant 'non-value-added time' in addition to transport cost, including a large carbon footprint and so reducing unnecessary attendance is vital for sustainability. ${ }^{1}$

There are six key principles in redesigning outpatient services:

1. Senior triage has to be enhanced. This is a process where referrals are reviewed by a senior clinical decision maker and assigned to a treatment or diagnostic pathway. This can be done remotely and uses a variety of techniques including distance consultations to make sure that the patient moves as efficiently as possible for a diagnostic or treatment pathway. For more details on how to do this, please refer to the BSG guidance on rebooting and redesigning gastroenterology outpatients (to be published on the BSG website). A study from Wolverhampton showed that enhanced senior triage can result in a reduction in costs as well as clinical benefits such as: $21 \%$ could be discharged back to primary care following initial investigations and $32 \%$ could be managed without a consultation. $^{9}$

2. Redesigning services is a team effort and requires the participation of the gastroenterology team including specialist nurses, physician associates, primary care, allied health professionals, administrators and management.

3. Although the COVID-19 pandemic has forced us to use telephone or virtual consultations, most of us have seen the benefits of this type of consultation for the patient and the clinician. ${ }^{6}$ Top tips and advice on how to successfully conduct these types of consultation are described in the BSG guidance on rebooting and redesigning outpatient services. ${ }^{1}$ However, there is still a need for faceto-face consultations for some situations, for example, where the examination is essential or there are significant communication difficulties. In addition, there are significant concerns that vulnerable patients are less likely to engage in remote consultations. ${ }^{1}$

4. An outpatient consultation (or event) with a patient, either virtual or face to face will comprise the following steps: reviewing referral letters, last clinic letter, relevant results; the consultation with the patient; the request of tests and prescribing; dictating a letter. The BSG job planning guidance document recommends that new patients will normally require $30 \mathrm{~min}$ and follow-up patients $20 \mathrm{~min}$ (BSG job planning guidance document, to be published on the BSG website). The gastroenterology team and managers should consider and agree on the time allocated for these consultations.

5. Having appropriate reliable, secure IT systems is essential in providing high-quality enhanced triage and remote consultations. The hospital needs to provide secure laptops/PCs with up-to-date software to allow video consultations in the workplace or at home. Adequate infrastructure including internet connectivity with an appropriate optimisation for video will be essential. Reliable IT service desks with regular maintenance of IT equipment is mandatory. Training of staff and patients to use these apps are necessary. Consideration must be given as to how to provide out of hours IT support for clinicians working flexibly. ${ }^{1}$

6. Job planning, including the recognition of flexible working, is key to ensuring that remote consultations are successfully implemented, especially outside standard working hours. Consultants may choose to work flexible sessions for several reasons such as for those with young families with child care needs, who may then choose to work more sessions during term time and take more time off during school holidays. Consultants can, with agreement from their employer, 'store up' extra sessions and take time off as a sabbatical. Annualised job plans can accommodate such a working patten including weekto-week timetable variation, other commitments that can occur on a slightly unpredictable basis and the need to have flexible sessions to help backfill endoscopy for example. ${ }^{1}$

At present, we need to increase the evidence base of the efficacy of the redesign of outpatients in relation to outcomes. Evaluation is necessary using methodologies such as service evaluation, quality improvement or audit.

\section{AUDIT}

Specific examples of outcomes to audit include: patient feedback/satisfaction, percentage requirement for face to face consultations, use of the Edinburgh Dysphagia Audit Tool ${ }^{10}$ for a 2-week wait/red flag upper gastrointestinal endoscopy triage; audit of inflammatory bowel disease (IBD) helplines renumber of patient calls and outpatient (OP) clinics or $\mathrm{A}+\mathrm{E}$ attendance avoided; Departmental review of redesigned pathways at 3 and 6 months using audit data to further improve local patient pathways using plan-do-study-act techniques. 
In conclusion, COVID-19 provides challenges but also a unique and powerful catalyst to reboot and redesign sustainable services to benefit patients and also improve the work-life balance of healthcare professionals. All these changes would not be possible without the cooperation of the hospital management team and like all good service reform, they should be part of the team approach. There is much innovative practice around the country that serves as exemplars and some of these are highlighted in the BSG Service Success Stories of the website. ${ }^{11}$

Contributors All authors contributed equally to the writing of this article.

Funding The authors have not declared a specific grant for this research from any funding agency in the public, commercial or not-for-profit sectors.

Competing interests None declared.

Patient consent for publication Not required.

Provenance and peer review Not commissioned; externally peer reviewed.

Open access This is an open access article distributed in accordance with the Creative Commons Attribution Non Commercial (CC BY-NC 4.0) license, which permits others to distribute, remix, adapt, build upon this work noncommercially, and license their derivative works on different terms, provided the original work is properly cited, appropriate credit is given, any changes made indicated, and the use is noncommercial. See: http://creativecommons.org/licenses/by-nc/4. $0 /$.

ORCID iD

Tony C Tham http://orcid.org/0000-0003-3304-0271

\section{REFERENCES}

1 BSG. BSG Guidance: rebooting gastroenterology and hepatology outpatients in the wake of COVID-19. Available: https://www.bsg.org.uk/covid-19-advice/bsg-guidancerebooting-gastroenterology-and-hepatology-outpatients-in-thewake-of-covid-19/

2 Gull N. F1 doctor, patient experience account, Bsg Webinar: how to get UK gastroenterology and liver services back on track, 2020. Available: https://www.bsg.org.uk/members-area/ bsg-webinar-how-to-get-uk-gastroenterology-and-liver-servicesback-on-track/

3 HSJ. Deaths of NHS staff from COVID-19 analysed. Available: https://www.hsj.co.uk/exclusive-deaths-of-nhs-staff-from-covid19-analysed/7027471.article

4 BMA. COVID -19: the risk to BAME doctors. Available: https://www.bma.org.uk/advice-and-support/covid-19/yourhealth/covid-19-the-risk-to-bame-doctors

5 Gleeson D, O'Shea C, Ellison H, et al. Stress and its causes in UK gastroenterologists: results of a national survey by the British Society of gastroenterology. Frontline Gastroenterol 2019;10:43-9.

6 BSG. Survey results: the effect of COVID-19 on gastroenterology. Available: https://www.bsg.org.uk/workforcereports/the-effect-of-covid-19-on-gastroenterology/

7 BSG. Workforce planning letter from GIRFT lead for GI and hepatology and the BSG president. Available: https://www.bsg. org.uk/covid-19-advice/workforce-planning-letter-from-girftlead-for-gi-and-hepatology-and-the-bsg-president/

8 BSG. BSG guidance on recommencing GI endoscopy in the deceleration and early recovery phases of the COVID-19 pandemic. Available: https://www.bsg.org.uk/covid-19advice/bsg-guidance-on-recommencing-gi-endoscopy-in-thedeceleration-early-recovery-phases-of-the-covid-19-pandemic/

9 Pelitari S, Hathaway C, Gritton D, et al. Impact and cost-effectiveness of formal gastroenterology outpatient referral clinical assessment service. Frontline Gastroenterol 2018;9:159-65.

10 Rhatigan E, Tyrmpas I, Murray G, et al. Scoring system to identify patients at high risk of oesophageal cancer. Br J Surg 2010;97:1831-7.

11 BSG. Success stories. Available: https://www.bsg.org.uk/ resource-type/success-story/ 